\title{
Article \\ Genome-Wide Transcriptomic Identification and Functional Insight of Lily WRKY Genes Responding to Botrytis Fungal Disease
}

\author{
Shipra Kumari ${ }^{1}$, Bashistha Kumar Kanth ${ }^{1}$, Ju young Ahn ${ }^{1,2}$, Jong Hwa Kim ${ }^{3}$ and Geung-Joo Lee ${ }^{1,2, *(1)}$ \\ 1 Department of Horticulture, Chungnam National University, Daejeon 34134, Korea; \\ shiprakumari11@yahoo.com (S.K.); bashistha_kanth@yahoo.com (B.K.K.); wnduds357@naver.com (J.y.A.) \\ 2 Department of Smart Agriculture Systems, Chungnam National University, Daejeon 34134, Korea \\ 3 Department of Horticulture, Kangwon National University, Chuncheon 24341, Gangwon-do, Korea; \\ jonghwa@kangwon.ac.kr \\ * Correspondence: gjlee@cnu.ac.kr
}

Citation: Kumari, S.; Kanth, B.K.;

Ahn, J.y.; Kim, J.H.; Lee, G.-J.

Genome-Wide Transcriptomic

Identification and Functional Insight of Lily WRKY Genes Responding to Botrytis Fungal Disease. Plants 2021, 10,776. https://doi.org/10.3390/ plants10040776

Academic Editor: Artur Alves

Received: 25 January 2021

Accepted: 12 April 2021

Published: 15 April 2021

Publisher's Note: MDPI stays neutral with regard to jurisdictional claims in published maps and institutional affiliations.

Copyright: (c) 2021 by the authors. Licensee MDPI, Basel, Switzerland. This article is an open access article distributed under the terms and conditions of the Creative Commons Attribution (CC BY) license (https:// creativecommons.org/licenses/by/ $4.0 /)$.

\begin{abstract}
Genome-wide transcriptome analysis using RNA-Seq of Lilium longiflorum revealed valuable genes responding to biotic stresses. WRKY transcription factors are regulatory proteins playing essential roles in defense processes under environmental stresses, causing considerable losses in flower quality and production. Thirty-eight WRKY genes were identified from the transcriptomic profile from lily genotypes, exhibiting leaf blight caused by Botrytis elliptica. Lily WRKYs have a highly conserved motif, WRKYGQK, with a common variant, WRKYGKK. Phylogeny of LlWRKYs with homologous genes from other representative plant species classified them into three groupsI, II, and III consisting of seven, 22, and nine genes, respectively. Base on functional annotation, 22 LIWRKY genes were associated with biotic stress, nine with abiotic stress, and seven with others. Sixteen unique $L I W R K Y$ were studied to investigate responses to stress conditions using gene expression under biotic and abiotic stress treatments. Five genes-LIWRKY3, LlWRKY4, LIWRKY5, LlWRKY10, and LlWRKY12-were substantially upregulated, proving to be biotic stress-responsive genes in vivo and in vitro conditions. Moreover, the expression patterns of LlWRKY genes varied in response to drought, heat, cold, and different developmental stages or tissues. Overall, our study provides structural and molecular insights into LIWRKY genes for use in the genetic engineering in Lilium against Botrytis disease.
\end{abstract}

Keywords: Botrytis disease; Lilium longiflorum; qRT-PCR; transcription factor; WRKY family

\section{Introduction}

Lilium spp. is one of the most important ornamental plants used for cut or potting flowers and gardening purposes. The current international trade of ornamental plants including Lilium is $£ 60-75$ billion and increases every year world-wide by $2-4 \%$ [1]. However, the lily is subject to a wide range of abiotic and biotic stresses, which have been worsened by global climate changes. Botrytis in Lilium is a common fungal disease affecting leaves, stems, and sometimes the flowers. The disease is dispersed by spores when splashed around by rain or watering. Botrytis affects firstly leaves, flower then bulb until the plant is affected three years consecutively [2]. Low temperature and high humidity cause necrotic lesions on lily leaves and petals, initiating rotting caused by Botrytis elliptica [3]. Fusarium oxysporum causes basal rot disease, developing black or brownish necrotic lesions on the bulb, resulting in bulb disintegration [4]. Thus, the quality and yield of Lilium are affected by various abiotic and biotic stresses. The drought stress in oriental lily cultivar 'Sorbonne' influences physiological and biochemical changes, resulting in shorter plants, smaller flowers, and shallower leaf color, affecting the quality of flowers [5]. The high temperature $\left(>30^{\circ} \mathrm{C}\right)$ reduces the quality of the cut flowers and leads to the degeneration of the bulb [6]. 
In addition, climatic variation has adverse effects on the ecological distribution of native Korean Lilium sp., leading to a steady decline in Lilium germplasm resources [7]. Therefore, it has become necessary to produce lily cultivars resistant to biotic and abiotic stresses to preserve lily resources world-wide.

RNA-Seq is a sequencing technique which uses next-generation sequencing (NGS) to reveal the presence and quantity of RNA in biological samples at a given moment, analyzing the continuously changing cellular transcriptome [8]. RNA-seq technology has been applied extensively in lily research to study differentially expressed genes (DEGs) in cold-stress response [9], flower color biosynthesis [10], and in vernalization [11]. Transcriptional regulation is the most useful link to study gene expression in plants. Transcription factors control various critical biological processes in gene transcription regulation networks $[12,13]$. The plant genome contains large number of genes acting as transcription factors, and at least 58 transcription factor families have been identified [14]. Approximately $8 \%$ of the genes in Arabidopsis and $4 \%$ in rice (Oryza sativa) have been identified as transcription factors $[15,16]$.

The WRKY family, named after the highly conserved WRKY domain, is the largest transcription factor family [17]. The WRKY domain is associated with approximately 60 amino acids and comprises the most conserved short peptide sequence, WRKYGQK, with an adjacent $\mathrm{C}_{2} \mathrm{H}_{2}$ or $\mathrm{C}_{2} \mathrm{HC}$ zinc finger structure. WRKYGQK has various variants, such as WRKYGKK, WRKYDQK, and WRKYDHK $[18,19]$. Depending on the number of WRKY domains and zinc finger types, WRKY families are divided into groups I, II, and III. Group I has two WRKY domains with one $\mathrm{C}_{2} \mathrm{H}_{2}$-type zinc finger $\left(\mathrm{C}-\mathrm{X}_{4}-{ }^{-}-\mathrm{C}-\mathrm{X}_{22}-23^{-}\right.$ $\left.\mathrm{H}-\mathrm{X}_{1}-\mathrm{H}\right)$, and group II has one WRKY domain with a $\mathrm{C}_{2} \mathrm{H}_{2}$-type zinc finger. Group II is further divided into five subgroups (IIa-e). Group III also has only one domain but with the $\mathrm{C}_{2} \mathrm{HC}$-type zinc finger $\left(\mathrm{C}-\mathrm{X}_{7}-\mathrm{C}-\mathrm{X}_{23}-\mathrm{H}-\mathrm{X}_{1}-\mathrm{C}\right)_{6}$. The WRKY gene family is one of the most crucial transcription factor families playing important roles in regulating developmental and physiological processes in plants [20]. SPF1 was the first WRKY gene reported from sweet potato (Ipomoea batatas) in 1994 [21]. Subsequently, several WRKY genes have been identified in parsley (Petroselinum crispum) [22], Arabidopsis [23], rice [24], in Lilium regale [25], Lilium oriental hybrid 'Sorborne' [26], Lilium pumilum [27], and Lilium longiflorum [28].

Along with other plants, the vegetatively propagating bulbing lily has a number of WRKY genes, and their organization and function are largely unknown. This study aimed to:

1. Systematically investigate WRKY genes in Lilium using the available transcriptome;

2. Study the gene composition, construction of an orthologous dataset, and protein structure of WRKY;

3. Explain the classification and evolutionary relationships among WRKY genes;

4. Study the expression profiles of LlWRKY genes in different developmental stages, tissues, and biotic and abiotic stress conditions to identify suitable candidate genes for further functional analysis.

This work provides novel insights into evolutionary relationships, protein structures, and the expression profile of LIWRKYs, which will help the further investigation of LIWRKY genes.

\section{Results and Discussion}

\subsection{In Silico Identification of the WRKY Gene Family}

The WRKY gene family, as important transcription factors, plays a pivotal role in the regulation of plant development, growth, and stress response [29]. The functions of several WRKY genes in Arabidopsis and other model crops have been systematically studied [30-33]. To explore the function and organization of LlWRKY genes in Lilium, transcriptome data were generated and used to identify WRKY genes through computational analysis. Using a BLAST search, a total of 38 unique transcripts with high similarity was found. These Lilium putative transcripts were analyzed using the NCBI-CDD web server to obtain conserved 
protein domain information on sequences. Moreover, sequences with complete WRKY domains were further analyzed via BLAST in NCBI to remove repeats. Finally, 38 unique LIWRKY gene sequences were identified including 24 full CDS (Table S1) and 14 partial CDS (Table S2), and detailed information of the LIWRKY domains is substantiated in Tables S5 and S6.

\subsection{Multiple Sequence Alignment, Protein Structure Prediction, and Conserved Motifs Analysis}

The protein sequence-structure analysis of LlWRKYs showed that 33 LlWRKYs usually contained the highly conserved sequence 'WRKYGQK.' LlWRKY26, -34, and -35 have an incomplete 'WRKYGQK' sequence, whereas $L I W R K Y 27$ and $L I W R K Y 37$ have an incomplete zinc finger domain. LIWRKY29 and -30 are deficient in the WRKY domain with a complete zinc finger domain in our study (Figure 1 and Table S5). Two LlWRKYs, LlWRKY15 and LIWRKY16, were the most common sequence variants of 'WRKYGKK' (Figure 1). Seven LIWRKY protein sequences varied in single amino acids in their WRKY domain. Sequences with such domains are widely distributed in several species [34,35]. Some WRKY domains have shown unusual variations, e.g., five unusual variations in grape (Vitis vinifera) VvWRKY and seven variations in wheat (Triticum aestivum) TaWRKY [19]. The WRKY domain is the most vital structure in WRKY proteins. The WRKY domain with the WRKYGQK domain interacts with the TTGACY core motif to activate downstream genes [17]. The variants in the WRKYGQK domain could influence the normal activity of DNA binding [36]. WRKY genes lacking the WRKYGQK domain recognize binding sequences excluding W-box elements. Tobacco (Nicotiana tabacuom) NtWRKY12 and soybean (Glycine max) GmWRKY6 proteins cannot bind to the W-box element but bind to WK-box (TTTTCCAC) [33]. In addition, variations can occur in the zinc finger domain of WRKY sequences. Three variations have been reported in three $V v W R K Y$ proteins. However, the function of the variants in the zinc finger domain is unknown, possibly influencing WRKY gene classification [19].

The MEME program predicted conserved motifs in LIWRKY proteins. The six identified motifs demonstrated WRKY protein structure in Lilium (Figure 2B). The details of six conserved motifs are shown in Figure S1 and the conserved sequences of motif 1 and motif 2 in Table S6. The number of motifs in LIWRKY protein ranged from 1 to 6 , and the length of motifs ranged from 6 to 50 amino acids. Additionally, six motifs, namely motifs 1, 2, 3, 4, 5, and 6, were found in the WRKY domain. Motif 5 was located outside the WRKY domain (Figure S1). Meanwhile, motif 1 was shared by LlWRKY4, -27, -37, and -38, whereas motif 2 was shared by five LlWRKYs: LlWRKY26, -29, -30, -34,-35. Ten LlWRKYs: LlWRKY2, -8, $-11,-12,-13,-14,-17,-18,-22$, and -25 shared motifs 1 and 2. Furthermore, LlWRKY19, -20, and -21 from group III all shared motifs 5, 3, 1, and 2. Motifs 6, 3, 1, and 2 were shared by LlWRKY5, -6, -9, and -10 from group IC.

\subsection{Classification and Phylogenetic Analysis}

The WRKY gene family is highly conserved in both dicots and monocots. Based on sequence similarity and protein structure, it is divided into three groups [20]. To categorize WRKY sequences and investigate evolutionary relationships in LlWRKY proteins, 38 putative LlWRKY proteins from Lilium, seven WRKY proteins from Arabidopsis, and 19 WRKY proteins from rice were selected for phylogenetic analysis. The phylogenetic analysis results in Figure 2A show that these LlWRKY proteins are categorized into Groups I, II, and III. Then, we analyzed the evolutionary relationship among LlWRKY and WRKYs of different plants, including Arabidopsis, rice, L. regale, L. hybrid div VII, and L. pumilum. The phylogenetic results showed that there exists close relationship of LlWRKY with WRKYS of L. regale, L. hybrid div VII, and L. pumilum (Figure S5). 


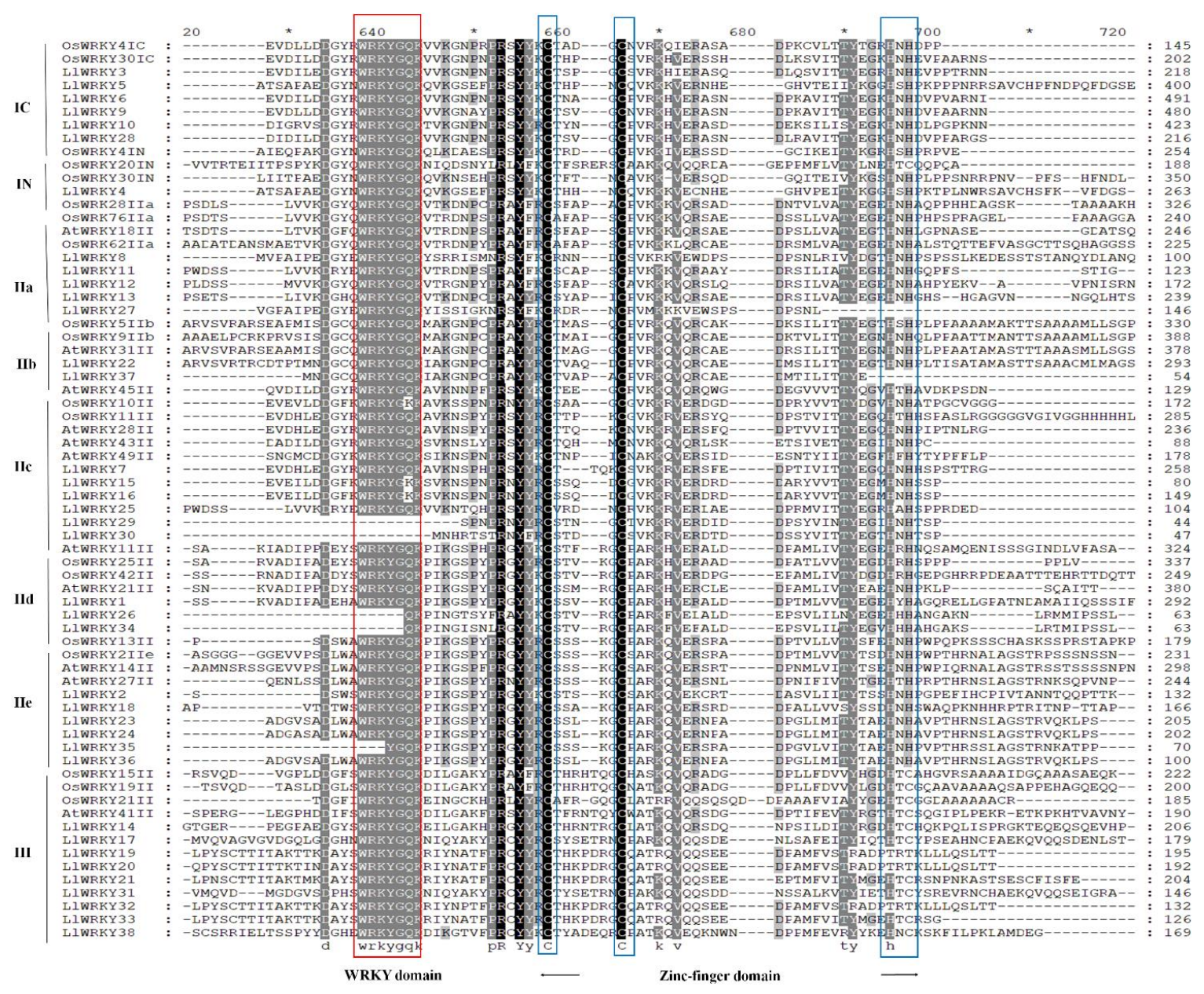

Figure 1. Multiple sequence alignment of various types of WRKY domains (I, II, and III) from Lillium (LlWRKY), Arabidopsis $(A t W R K Y)$, and rice (OsWRKY). Identity, similarity, and deletions among WRKY alignments are indicated by black and grey shades and hyphens, respectively. A red box represents the WRKY domain and a blue box the zinc finger domain. $\mathrm{N}$ means $\mathrm{N}$-terminal and $\mathrm{C}$ means C-terminal.
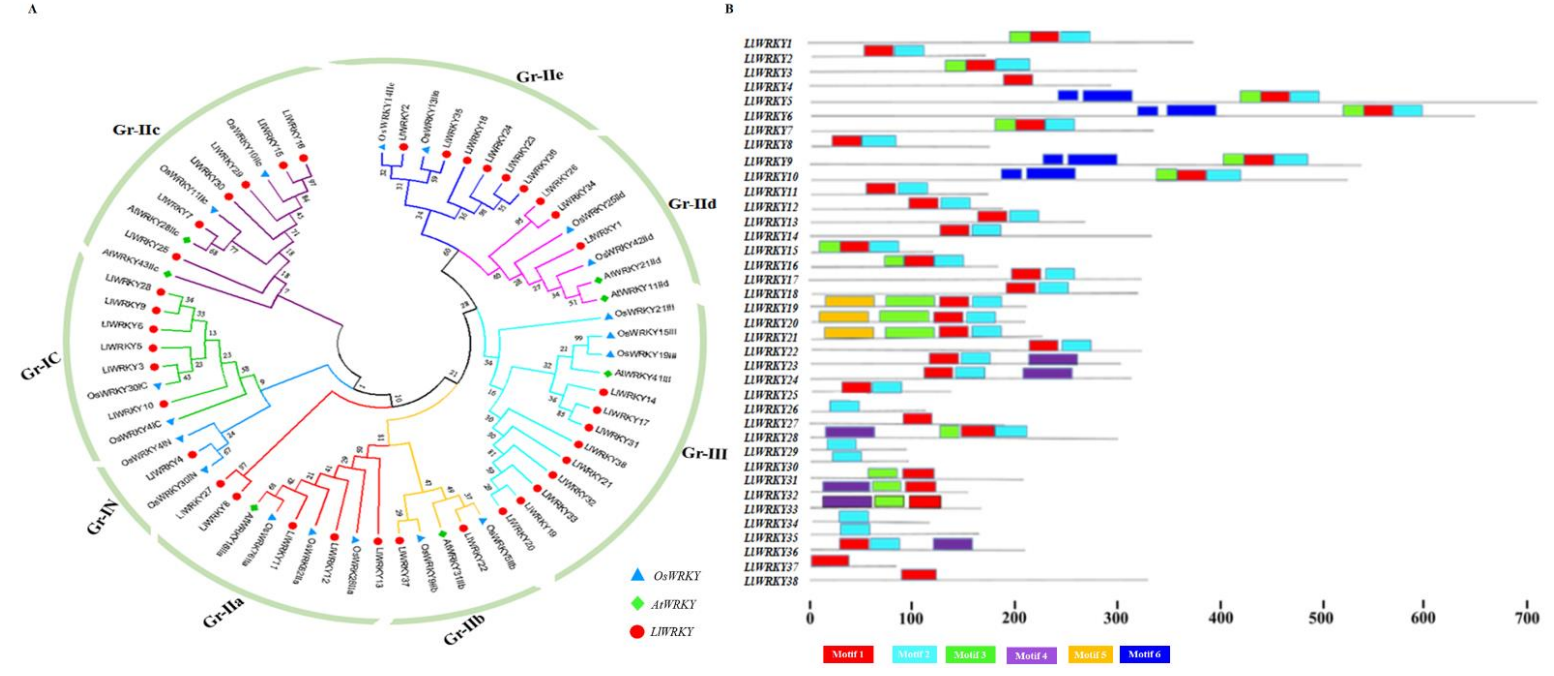

Figure 2. Unrooted phylogenetic tree analysis of WRKY proteins: (A) Lilium (38), rice (19), and Arabidopsis (7); (B) conserved motifs of 38 LlWRKY proteins. The phylogenetic tree was constructed using MEGA7. Different colors represent different groups and red circles represent LIWRKY, blue triangles represent OsWRKY and green squares represent AtWRKY proteins. MEME was used to predict motifs, and boxes represent these motifs. 
Seven LlWRKY proteins constituted Group I, including sequences with two WRKY domains and one zinc finger motif, $\mathrm{C}_{2} \mathrm{H}_{2}\left(\mathrm{C}-\mathrm{X}_{4}-\mathrm{C}-\mathrm{X}_{22}-23^{-} \mathrm{HXH}\right)$. The $22 \mathrm{LlWRKY}$ proteins contained one WRKY domain and only one zinc-binding motif, $\mathrm{C}_{2} \mathrm{H}_{2}\left(\mathrm{C}-\mathrm{X}_{4}-5-\mathrm{C}-\mathrm{X}_{23}-\mathrm{HXH}\right)$, constituting group II. The remaining nine $L l W R K Y$ proteins were assigned to group III, with a single $W R K Y$ domain and $\mathrm{C}_{2} \mathrm{CH}\left(\mathrm{C}-\mathrm{X}_{7}-\mathrm{C}-\mathrm{X}_{23}-\mathrm{HXC}\right)$ zinc-binding motif. According to the WRKY subgroup classification in rice and Arabidopsis, group II of LlWRKYs is further divided into five subgroups: group IIa (5), IIb (2), IIc (6), IId (3), and IIe (6).

\subsection{Functional Annotation of LIWRKY Based on the Orthologous Gene in Lilium and Rice}

There are two types of homologous genes, orthologs and paralogs. Ortholog genes have diverged through speciation in different species, whereas paralog genes are duplicated in a single species. Orthologs are widely distributed in species and are assumed to elicit equivalent biological functions sharing key properties with other species [37]. Various methods are available to identify orthologous genes to study their function [38]. Phylogenetic analysis is a rapid, simple, and relatively accurate approach to evaluate orthologs widely present in different organisms.

Several orthologous genes have been identified in L. longiflorum- LIWRKYs (Table S3). Among them, one LIWRKY7 gene has only one homolog gene-OsWRKY36 in rice. Other Lilium genes have several homologous OsWRKY genes in rice. LIWRKY14, -17, -19, -20, -21, $-31,-32,-33$, and -38 are homologous genes to OsWRKY19, -22, -55, and -74 (Figure 3). At the same time, several Lilium LIWRKY genes have similar homologous genes in rice. LIWRKY1, $-2,-18,-23,-24,-26,-34,-35,-36$, and -37 have the same homologous genes: OsWRKY13, -14 , $-17,-39$, and -68 in rice (Figure 3). Gene function can be putatively predicted according to their homology, as the functions of several OsWRKYs have been extensively studied [22,29].

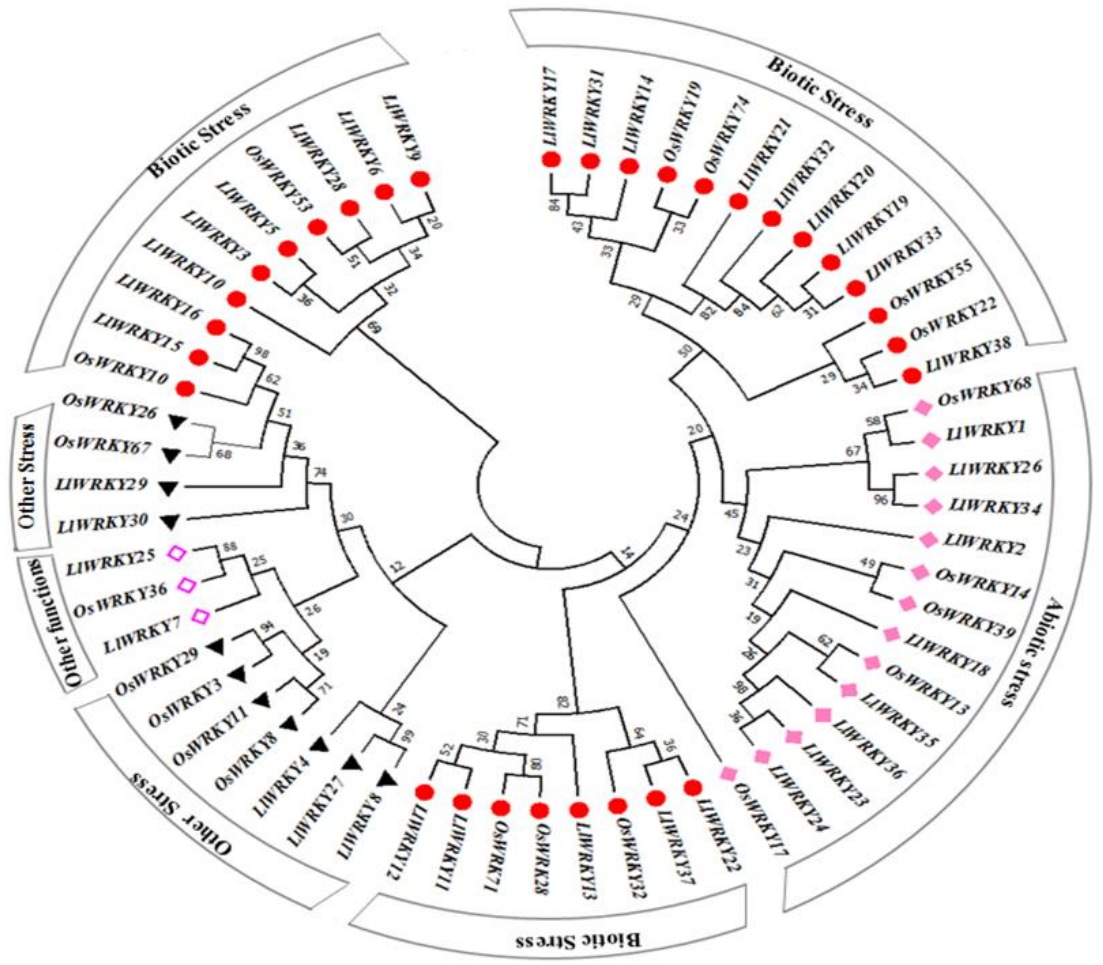

Figure 3. Functional grouping of the annotated LIWRKY proteins based on the homologous gene information regarding biotic stress-responsive genes. The unrooted phylogenetic tree was constructed for Lilium longiflorum and rice proteins to identify homologous gene pairs. Red circles represent the responsive genes to biotic stress; pink squares, black triangles, and magenta squares represent genes responsive to abiotic stress-responsive, other stresses, or possessing other functions, respectively. 
In Oryza sativa, transgenic lines deficient in OsWRKY-36 and OsWRKY-102 genes and double-mutant lines OsWRKY36/OsWRKY102 significantly increased the lignin content. They are associated with the repression of rice lignification [39]. Over-expression of the stress-induced OsWRKY45 enhances disease resistance and drought tolerance in Arabidopsis [32]. PheWRKY1, homologous of OsWRKY10, a gene from moso bamboo (Phyllostachys edulis), enhances disease resistance in transgenic Arabidopsis thaliana [40]. Overexpression of $\operatorname{LrWRKY} 4$ gene significantly increased root-length and enhanced resistance against B. cinerea in Arabidopsis [25]. Similarly, overexpression of LlWRKY39 gene in L. longiflorum seems to be related to protect cells from high temperature [28]. The homologous OsWRKY proteins in rice have been used as a reference to explore the potential roles of LlWRKYs. Based on functional annotation of rice homolog genes, four groups of LlWRKYs were identified (Figure 3). Of these, nine LlWRKY genes were involved in abiotic stress responses. In addition, $22 L L W R K Y_{S}$ were found to be involved in biotic stress responses, and the remaining seven $L I W R K Y_{S}$ in other stresses and other functions.

Several WRKY genes have been studied for their response to abiotic and biotic stress [41,42]. In Lilium regale, 23 LrWRKY genes with complete WRKY domains have been identified. Six LrWRKY genes was induced by B. cinerea infection. LrWRKY4, LrWRKY8, and LrWRKY10 were expressed to higher levels, while LrWRKY6 and LrWRKY12 were expressed to lower levels. LrWRKY4 and LrWRKY12 genes were responsive to salicylic acid (SA) and methyl jasmonate (MeJA) treatments [25].

Approximately 51\% of AtWRKY genes from Arabidopsis in roots showed high expression under salt stress [43], and 57\% of OsWRKY were differentially expressed under drought, cold, and salt stress [44], whereas 70-90\% of $V v W R K Y$ genes were differentially expressed under various abiotic or biotic stresses [19].

\subsection{Expression Analysis of LlWRKY Genes under Biotic Stresses in Lilium Longiflorum}

Nine genes, LlWRKY3, -5, -6, -9, -10,-11,-12, -13, and -20, are associated with biotic stresses and one, LIWRKY4, related to another function were selected to determine the expression profiles in vivo (in field) and in vitro (laboratory) after B. elliptica infection. As shown in Figure 4A,B, the selected LIWRKY genes were induced to biotic stresses. All LIWRKY genes showed higher expression than uninfected L. longiflorum. In particular, LIWRKY3, -4, -5, -10, and -12 had high expression levels in response to B. elliptica infection under both conditions-in vivo and in vitro. LIWRKY4 showed a significantly high expression after B. elliptica infection in vivo and in vitro (Figure $4 \mathrm{~A}, \mathrm{~B}$ ). In in vivo analysis, the expression levels of five LIWRKY genes in infected leaf highly increased in comparison to un-infected leaf. The gene LIWRK4 shows the highest expression-an increase by 152.287fold. Similarly, LIWRKY10, -5, and -3 showed a 36.286-, 36.062-, and 17.296-fold increase, respectively. In in vitro analysis, LIWRKY4 gene shows the highest expression, 30.1789fold. Other genes showed expression in the following order: LIWRKY10>LlWRKY5> LlWRKY12 > LlWRKY3. In in vivo and in vitro condition both, LlWRKY6, -9, -11, -13, and -20 showed slight expression. Most of the LIWRKY genes from L. longiflorum have more expression in the in vivo condition than expression in the in vitro condition because of the natural environments. Plants in their natural habitat are constantly subjected to multiple fluctuating environmental factors, and complex genetic regulatory networks are functioning in them.

Furthermore, it has been found that orthologous genes OsWRKY4 and OsWRKY30 were related to group I. OsWRKY30 gene overexpression increased the resistance to $M$. oryzae and $R$. solani, possibly activating various downstream genes, including jasmonic acid (JA) biosynthesis pathway genes [45]. OsWRKY4 acts as a transcriptional activator and responds to defense against $R$. solani [46]. LIWRKY4, associated with other functions during functional annotation, is highly responsive to Botrytis infection. 
A

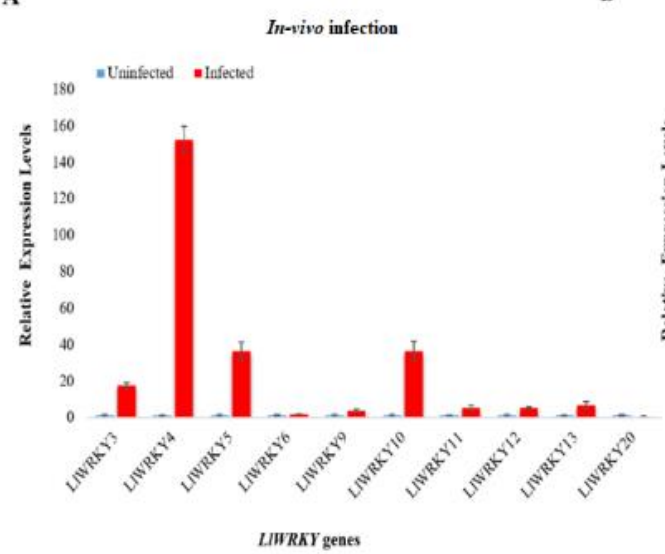

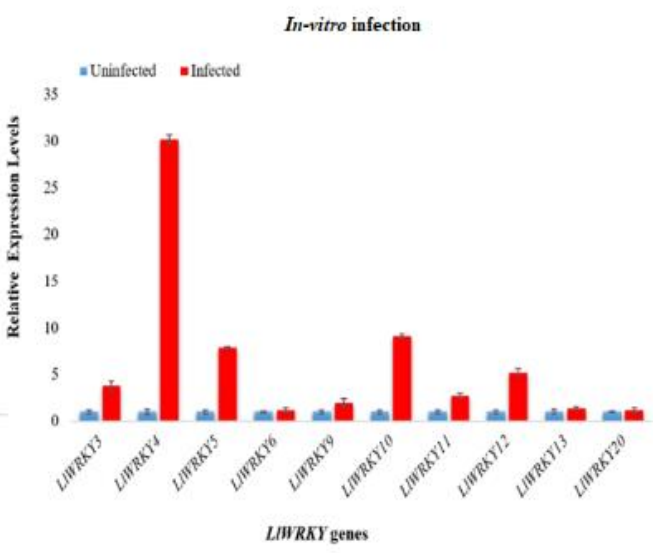

Figure 4. Comparative expression patterns of the selected LlWRKY genes in response to Botrytis elliptica infection investigated under (A) in vivo and (B) in vitro conditions. Error bars indicate the standard error of three biological replicates and the expression levels were normalized against the level of actin.

OsWRKY31 gene overexpression enhances disease resistance, affects auxin response, and affects root growth in transgenic rice [47]. GhWRKY15, identified in cotton (Gossypium hirsutum), is involved in plant development and disease resistance [48]. After Botrytis infection, expression analyses helped screen WRKY genes that might be involved in natural resistance against Botrytis infection in Lilium.

\subsection{Expression Profiles of LlWRKY Genes under Abiotic Stresses}

WRKY genes were found to confer to abiotic stress resistance, as reported by Chen [49]. Based on the transcriptome data and their orthologous gene information under different abiotic stresses (Table S3), we selected LlWRKY genes associated with abiotic or biotic stress to analyze their expression characteristics [50]. LIWRKY4, -7, -8, and -18 genes exhibited higher responses to drought stress in 10-d samples, whereas LlWRKY1, -2, -3, -20, and -22 were weakly expressed in 5-d-old samples. However, LIWRKY3, -22, and -8 did not express well in 5- and 10-d samples (Figure S3A). LlWRKY1, -2, and -4 genes were upregulated in heat treatments, maintaining a high expression level at 6 and $12 \mathrm{~h}$, whereas $L l W R K Y 7$ was not sensitive to high-temperature treatment (Figure S3B). Moreover, LlWRKY1 and LIWRKY7 were highly expressed under cold treatment by more than 100 times. However, the expression level of LIWRKY1 and LIWRKY7 initially increased and reached a maximum after $24 \mathrm{~h}$ (Figure S3C). The expression of OsWRKY76 was induced by low temperature; OsWRKY76 overexpression improved tolerance to cold stress in rice plants [51]. Some OsWRKY genes are induced by drought, salt, heat stress, and cold [24]. OsWRKY69 specifically binds to ABL1, which regulates rice stress responses [52].

\subsection{Tissue-Specific Expression Patterns of LlWRKY Genes}

The expression levels of 10 LIWRKY genes were analyzed via qRT-PCR in leaf, bud, stem, flower, stigma, internode, and root of lily (Figure S4). Most of the LlWRKY genes clearly showed tissue-specific expression. LIWRKY4, -5, -6, -9, -11, -12, and -13 had higher expression in buds, stems, and roots, whereas LIWRKY-10 and LIWRKY-20 showed relatively lower expression levels in stems and roots, respectively. Furthermore, some LlWRKY genes did not show significant differences in expression levels. Additionally, some LIWRKY genes showed consistent levels of tissue-specific expression patterns and relatively strong expression in buds, stems, and roots.

DcWRKY3, -8, -24, -64, and -88 from carrot (Daucus carota) are involved in root development, while DcWRKY3 and DcWRKY8 also play an important role in plant development [53]. Similarly, OsWRKY78 was reported to participate in regulating of stem elongation in rice [54]. In our study, $\operatorname{LIWRKY3},-4,-5,-6,-9$, and -10 were highly expressed at $40 \mathrm{~d}$ of development stage, and $\operatorname{LlWRKY} 3,-4,-5,-6$, and -20 at $120 \mathrm{~d}$, while only $\mathrm{Ll}-$ 
WRKY20 was highly expressed at $60 \mathrm{~d}$ (Figure S2). The similar results showed in carrot and Arabidopsis, in which expression patterns of different WRKY genes depended on plant development or leaf stages, which seems to be associated with different roles in intracellular signaling by specific DNA binding features [53]. Our result provided basic clues on LIWRKY genes playing functional roles during the growth and development in Lilium.

\section{Materials and Methods}

\subsection{Plant Materials}

All plant materials were obtained from Kangwon National University, Chuncheon, Gangwon-do, Korea. Plants with brown spots or fuzzy, grayish mold on leaves, buds, and flower petals were selected first, and whole plants were collected at 8:00 am from fields of the University. Five leaves from each plant were taken for the experiments. Samples were kept in a $-80{ }^{\circ} \mathrm{C}$ freezer until liquid nitrogen was used. RNA was isolated from approximately $1.0 \mathrm{~g}$ of leaf tissue using a Hybrid-R ${ }^{\mathrm{TM}}$ Total RNA isolation kit (GeneAll, Daejeon, Korea). The quantity and quality of RNAs were determined using a NanoDrop Lite spectrophotometer (Thermo Fisher Scientific, Waltham, MA, USA). cDNA synthesis was conducted using the TruSeq mRNA sample preparation kit. Sequencing libraries were prepared according to the manufacturer's instructions (Illumina) for cluster analysis and sequenced using Illumina $\mathrm{HiSeq}^{\mathrm{TM}} 2500$ sequencing technology (Illumina). Illumina paired-end reads were trimmed using the Dynamic Trim of SolexaQA software package. Transcripts were assembled using Trinity. In the gene annotation process, gene expression values were normalized using the DESeq software package. The assembled total sequences of Lilium were annotated in the NCBI database using BLASTX.

\subsection{Identification of WRKY Gene Family in L. longiflorum}

Transcriptomic data from Illumina sequencing reads were deposited at the National Agricultural Biotechnology Information Center (NABIC) (accession: NN-3727-000001 and 3728-000001). A total of 38 WRKY gene sequences of L. longiflorum were obtained from our RNA sequence data above (unpublished). For the transcription factor (TF) annotation, the TF database (PlantTFDB) version 4.0 was used and classified into families. WRKY gene sequences were queried against the PFAM (http:/ / pfam.xfam.org/search accessed on 15 February 2021) and CDD (http:/ / www.ncbi.nlm.nih.gov/Structure/cdd/wrpsb.cgi accessed on 15 February 2021) databases to search for their putative protein domain features. Open reading frames (ORFs) of WRKY gene sequences were obtained using the NCBI's ORF finder. Subcellular localization of WRKY proteins was predicted using TargetP 1.1 and SignalP 4.1 [55]. Theoretical pI/molecular weight of proteins was obtained using the Compute pI/Mw tool on the ExPASy platform (http:/ / web.expasy.org/compute_pi/ accessed on 15 February 2021).

\subsection{Multiple Sequence Alignment, Protein Structure Prediction, and Conserved Motifs Analysis}

Arabidopsis thaliana and rice WRKY genes were obtained from previous studies [56]. The evolutionary relationships among these $W R K Y$ s were investigated by aligning predicted amino acid sequences of WRKY genes from L. longiflorum with the WRKY genes of other species using the ClustalX program, and sequence identity and similarity were obtained. LlWRKY gene families were obtained using the MEME tool (http:/ / meme.nbcr.net/ 15 February 2021) [57] with the following parameters: 0 or 1 motifs per sequence, minimum amino acid motif size of 6 and maximum of 50, and 2-6 optimum amino acid sites for each motif.

\subsection{Phylogenetic Analysis}

Using a dataset of 64 predicted amino acid sequences of the WRKY gene family members from Lilium and different plant species, sequence alignment was conducted using MEGA7 [58] of the MUSCLE program [59] with the following parameters: maximum 
iterations 1000; hydrophobicity 1.2; gap open 1. MUSCLE align sequences were based on multiple sequence comparison by log-expectation.

For phylogenetic analysis, the alignments made above were imported into MEGA7. A maximum-likelihood tree, based on the Jones-Taylor-Thornton model was built with a pairwise deletion option and 1000 bootstrap replicates, and the evolutionary relationships among LlWRKY gene family members were determined.

\subsection{Abiotic and Biotic Stress Treatments}

Abiotic stress treatment. Selected Bulbs of Lilium longiflorum were planted in 9-cm pots filled with soil $\left(v / v / v, 1: 1: 1=\right.$ sterile peat: vermiculite: perlite) at $24 / 16^{\circ} \mathrm{C}$ temperatures in a day/night cycle with a $16 / 8 \mathrm{~h}$ photoperiod in a growth chamber for six weeks.

For cold and hot stress, $4{ }^{\circ} \mathrm{C}$ growth chamber for cold treatment and $40{ }^{\circ} \mathrm{C}$ growth chamber for heat treatment was separately maintained before use. Six-week-old plants were kept in a cold chamber and a hot chamber for $24 \mathrm{~h}$. Leaf samples were collected at 0 , $1,6,12$, and $24 \mathrm{~h}$ during stress treatment. These samples were immediately kept into liquid nitrogen and stored at $-80^{\circ} \mathrm{C}$ for RNA isolation. For drought stress, six-week-old plants were kept in a growth chamber maintained at $24 / 16^{\circ} \mathrm{C}$ temperatures in day/night cycle, with $65 \%$ relative humidity, and with a $16 / 8 \mathrm{~h}$ photoperiod. During drought treatments, control plants were watered every $2 \mathrm{~d}$, treatment plants were watered every $5 \mathrm{~d}$ and 10 $\mathrm{d}$ for mild and severe drought stress treatments, respectively. The soil moisture content was measured before and after drought treatment using SM150 Moisture meter (Delta-T Devices, Cambridge, Great Britain). At the beginning of drought stress, the soil water content was recorded $30 \%$ for control, $10 \%$ on the 5 th $\mathrm{d}$, and $3 \%$ on the 10 th d during the stress period. Leaf samples were collected from the control and drought treated plants- the 5 th $\mathrm{d}$ and the 10th $\mathrm{d}$; then, samples were immediately frozen in liquid nitrogen and stored at $-80^{\circ} \mathrm{C}$.

Biotic stress treatment. Scales of the bulb of Lilium longiflorum were washed with tap water, then sterilized by ethanol $70 \%(v / v)$ for $30 \mathrm{~s}$, rinsed five times with distilled water, and placed in sodium hypochlorite $10 \%$ for $5 \mathrm{~min}$, then washed five times with sterilized distilled water. Scales were cultured in MS medium [60], supplemented with $0.1 \%$ myo-inositol, $3 \%$ sucrose, and $0.7 \%$ agar, for three weeks for the proliferation of blub. Then, scales were transferred to MS medium, supplemented with 3\% sucrose, $0.1 \%$ myo-inositol, and $0.7 \%$ agar, for 3 weeks to obtain leaves. Cultures were placed in incubation room at the $24 \pm 2{ }^{\circ} \mathrm{C}$ under $16 / 8 \mathrm{~h}$ light (a fluence rate of $240 \mu \mathrm{mol} \cdot \mathrm{m}^{-2} \cdot \mathrm{s}^{-1}$ )/ dark cycles during all stage.

B. elliptica (KACC43461) isolate was grown on petri dish containing $8 \%$ potato dextrose agar (PDA) (Becton, Dickinson and Co., USA) at $25^{\circ} \mathrm{C}$ under UV light $12 / 12 \mathrm{~h} \mathrm{light/dark}$ cycle for one weeks before use. Then, sterile distilled water $(10 \mathrm{~mL})$ was added to suspend the mycelium. Spore suspension were stained with methylene blue and spore-density was measured by a hemocytometer on an optical microscope (Nikon). The concentration of spore suspensions was adjusted to reach final concentrations of $2.0 \times 10^{4}$ spores $\cdot \mathrm{mL}^{-1}$.

The detached leaves from 3-week-old Lilium plant were washed three times with sterile distilled water, after which leaves were placed in a cell culture plate containing spore suspension of B. elliptica spores $\left(2.0 \times 10^{4}\right.$ spores $\left.\cdot \mathrm{mL}^{-1}\right)$ and inoculated at $25^{\circ} \mathrm{C}$ for $12 \mathrm{~h}$ in the dark. Then, leaves were washed with $70 \%$ ethanol after inoculation and cultured on $0.7 \%$ agar plates in a $16 / 8 \mathrm{~h}$ light (fluency density of $130 \mu \mathrm{mol} \mathrm{m}{ }^{-2} \cdot \mathrm{s}^{-1}$ at $25^{\circ} \mathrm{C}$. Sterile distilled water was used as a control for $B$. elliptica treatment. Disease symptoms were detected and assessed at 3,5, and $7 \mathrm{~d}$ after inoculation (DAI). The disease index was measured by the percentage of lesion areas compared to control leaves, which were placed in sterile distilled water. The disease index (DI) was divided into $0-4$ according to how much leaf area is infected; $0=$ no lesions observed, $1=1-10 \%, 2=11-25 \%, 3=26-50 \%$, and $4=$ over $50 \%$ of the leaf area infected [61]. Total RNA was extracted from both uninfected and infected leaves for qRT-PCR analysis. 


\subsection{RNA Isolation and $q R T-P C R$}

Total mRNAs were isolated from normal and differently stressed treated tissues including mature and young leaves, stems, and roots using a Hybrid-R $\mathrm{R}^{\mathrm{TM}}$ Total RNA isolation kit (GeneAll, Daejeon, Korea), as described in the manufacturer's instructions. cDNA was synthesized from extracted total RNA using PrimeScript ${ }^{\circledR}$ RT reagent with gDNA eraser kit (Takara Korea Biomedical, Seoul, Korea). Gene-specific qRT-PCR primer pairs for all 16 LlWRKY genes were designed using the Primer3plus web tool (http:/ / www. bioinformatics.nl/cgi-bin/primer3plus/primer3plus.cgi accessed on 15 February 2021) (Table S4). A 20- $\mu \mathrm{L}$ reaction volume was prepared containing $2 \mu \mathrm{L}$ of reverse-transcribed cDNA, SYBR ${ }^{\circledR}$ Green mix (PhileKorea, Daejeon, Korea), and $0.5 \mu \mathrm{M}$ of gene-specific forward and reverse primers. To estimate the relative RNA expression level, PCR reactions with parameters: one cycle at $95^{\circ} \mathrm{C}$ for $3 \mathrm{~min}, 40$ cycles of $95^{\circ} \mathrm{C}$ for $15 \mathrm{~s}, 60^{\circ} \mathrm{C}$ for $20 \mathrm{~s}$, and $72{ }^{\circ} \mathrm{C}$ for $15 \mathrm{~s}$, a cycle at $65^{\circ} \mathrm{C}$ for $5 \mathrm{~s}$, and a final cycle of $95^{\circ} \mathrm{C}$ for $2 \mathrm{~s}$, were performed with SYBR Green-based qRT-PCR using an Eco ${ }^{\mathrm{TM}}$ Real-Time PCR System (Illumina, Seoul, Republic of Korea) to detect primer specificity based on melt curve analysis and 1\% agarose gel electrophoresis for the amplification product. For each gene, three biological replicates with three technical replicate PCR reactions were conducted. The expression levels of candidate genes were normalized against the housekeeping gene actin-like gene LP59 from Lilium longiflorum accession DQ019459 [1] using the $2^{-\Delta \Delta C T}$ method [62].

\section{Conclusions}

In this study, 38 LlWRKY genes were identified and studied to investigate the organization and abundance of WRKY in Lilium. These LlWRKYs were analyzed for protein structure, figuring out related motifs, genes classification according to their functions, and phylogenetic relationships by comparing with model plants. Furthermore, after a comparison with other plants, orthologous gene analysis predicted the biological function of LlWRKYs. Finally, qRT-PCR analysis using transcriptional profiles was performed in various tissues under biotic and abiotic stresses, demonstrating tissue-specific and stressresponsive $L I W R K Y$ s. This study provides helpful information for further investigation of the function of LlWRKY in lily as stress-tolerant genes.

Supplementary Materials: The following are available online at https://www.mdpi.com/article/ 10.3390/plants10040776/s1, Figure S1: Sequence logos of the LIWRKY domain obtained from a MEME server after submitting the LIWRKY protein domains. The total height of the stack was used to show "information content" of that position in the motif. The height of the letters in the stack indicates the probability of each amino acid at that position. Figure S2: Expression patterns of LIWRKY genes from leaf samples of lily at different development stages grown for 20, 40, 60, and 120 d. Figure S3: Comparison of expression profiles of the selected LIWRKY genes under different abiotic stresses (A) drought stress, (B) heat stress at $40{ }^{\circ} \mathrm{C}$, and (C) cold stress at $4{ }^{\circ} \mathrm{C}$. Figure S4: Expression level of the identified LIWRKY genes in different tissues of Lilium longiflorum inoculated with Botrytis elliptica in vitro. Figure S5: Phylogenetic relationship of LIWRKY with WRKYs of other plants was analyzed by the neighbor-joining method with 1000 bootstrap replicates. Red circles represent LIWRKY, sky blue squares represent rice, green squares represent Arabidopsis, pink triangles represent $L$. regale, blue triangles represent $L$. hybrid div VII, and triangles represent L. pumilum WRKY proteins. Table S1: Table S1: Molecular sequence characteristics of LlWRKY (Full CDS) gene family in Lilium longiflorum. Table S2: Molecular sequence characteristics of LIWRKY (Partial CDS) gene family in Lilium longiflorum. Table S3: The identified LIWRKY proteins in Lilium longiflorum and their putative orthologous gene in rice. Table S4: Primers of 16 LlWRKY genes for qRT-PCR. Table S5: Domain characteristics of the 38 LIWRKY proteins. Table S6: The sequences of conserve motifs were identified using the program MEME.

Author Contributions: Conceptualization, S.K. and G.-J.L.; data curation, S.K. and B.K.K.; formal analysis, S.K. and G.-J.L.; funding acquisition, G.-J.L.; investigation, S.K. and B.K.K.; methodology, S.K., B.K.K. and G.J.L.; project administration, G.-J.L.; resources, J.H.K.; software, S.K., J.y.A. and B.K.K.; visualization, S.K. and J.y.A.; writing—original draft, S.K.; writing—review and editing, B.K.K., J.y.A. and G.-J.L. All authors have read and agreed to the published version of the manuscript. 
Funding: This research was funded by the Basic Science Research Program (NRF-2020R1A2C1015119) through the National Research Foundation (NRF) of Korea funded by the Ministry of Science and ICT and New Breeding Technologies Development Program (No. PJ01485802), Rural Development Administration, Republic of Korea.

Data Availability Statement: The data are available in the article and supplementary materials.

Conflicts of Interest: The authors declare no conflict of interest.

\section{References}

1. De Cáceres González, F.F.N.; Davey, M.R.; Sanchez, E.C.; Wilson, Z.A. Conferred resistance to Botrytis cinerea in Lilium by overexpression of the RCH10 chitinase gene. Plant Cell Rep. 2015, 34, 1201-1209. [CrossRef] [PubMed]

2. Doss, R.P.; Chastagner, G.A.; Riley, K.L. Streaking of lily leaves associated with infection by Botrytis elliptica. Plant Dis. 1988, 72, 859-861. [CrossRef]

3. Chiou, A.L.; Wu, W.S. Isolation, identification and evaluation of bacterial antagonists against Botrytis elliptica on lily. J. Phytopathol. 2001, 149, 319-324. [CrossRef]

4. Jang, J.-Y.; Moon, K.-B.; Ha, J.-H.; Park, J.-S.; Kim, M.-J.; Jeon, J.-H.; Lee, G.-J.; Kim, H.-S. Development of an efficient in vitro screening method for selection of resistant lily cultivars against Fusarium oxysporum f. sp. Lilii. Korean J. Hortic. Sci. Technol. 2015, 33, 883-890. [CrossRef]

5. Cui, G.-F.; Du, W.-W.; Duan, Q.; Wang, X.-N.; Ma, L.-L.; Wu, L.-F.; Jia, W.-J. Effects of drought stress at the bud stage on quality of cut lily. Chin. J. Appl. Ecol. 2016, 27, 1569-1575.

6. Gong, B.; Yi, J.; Wu, J.; Sui, J.; Khan, M.A.; Wu, Z.; Zhong, X.; Seng, S.; He, J.; Yi, M. LlHSFA1, a novel heat stress transcription factor in lily (Lilium longiflorum), can interact with LIHSFA2 and enhance the thermotolerance of transgenic Arabidopsis thaliana. Plant Cell Rep. 2014, 33, 1519-1533. [CrossRef] [PubMed]

7. Park, J.T.; Hwang, Y.J.; Lee, H.I.; Younis, A.; Lim, K.B. Ecological analysis of Lilium tsingtauense native in Korea. Hort. Environ. Biotechnol. 2014, 55, 230-236. [CrossRef]

8. Wang, Z.; Gerstein, M.; Snyder, M. RNA-Seq: A revolutionary tool for transcriptomics. Nature Reviews. Genetics 2009, 10, 57-63.

9. Wang, J.; Wang, Q.; Yang, Y.; Liu, X.; Gu, J.; Li, W.; Ma, S.; Lu, Y. De novo assembly and characterization of stress transcriptome and regulatory networks under temperature, salt and hormone stresses in Lilium lancifolium. Mol. Biol. Rep. 2014, 41, 8231-8245. [CrossRef] [PubMed]

10. Xu, L.; Yang, P.; Feng, Y.; Xu, H.; Cao, Y.; Tang, Y.; Yuan, S.; Liu, X.; Ming, J. Spatiotemporal transcriptome analysis provides insights into bicolor tepal development in Lilium "tiny Padhye". Front. Plant Sci. 2017, 8, 398. [CrossRef] [PubMed]

11. Villacorta-Martin, C.; Haan, J.D.; Huijben, K.; Passarinho, P.; Hamo, L.B.; Zaccai, M. Whole transcriptome profiling of the vernalization process in Lilium longiflorum (cultivar white heaven) bulbs. BMC Genom. 2015, 16, 1-16. [CrossRef] [PubMed]

12. Valliyodan, B.; Nguyen, H.T. Understanding regulatory networks and engineering for enhanced drought tolerance in plants. Curr. Opin. Plant Biol. 2006, 9, 189-195. [CrossRef]

13. Hobert, O. Gene regulation by transcription factors and microRNAs. Science 2008, 319, 1785-1786. [CrossRef] [PubMed]

14. Jin, J.P.; Zhang, H.; Kong, L.; Gao, G.; Luo, J.C. Plant TFDB 3.0: A portal for the functional and evolutionary study of plant transcription factors. Nucl. Acids Res. 2014, 42, D1182-D1187. [CrossRef] [PubMed]

15. Riechmann, J.L.; Heard, J.; Martin, G.; Reuber, L.; Jiang, C.; Keddie, J.; Adam, L.; Pineda, O.; Ratcliffe, O.J.; Samaha, R.R. Arabidopsis transcription factors: Genome-wide comparative analysis among eukaryotes. Science 2000, 290, 2105-2110. [CrossRef]

16. Goff, S.A.; Ricke, D.; Lan, T.H.; Presting, G.; Wang, R.; Dunn, M.; Glazebrook, J.; Sessions, A.; Oeller, P.; Varma, H.; et al. A draf sequence of the rice genome (Oryza sativa L. ssp. japonica). Science 2002, 296, 92-100. [CrossRef]

17. Eulgem, T.; Rushton, P.J.; Robatzek, S.; Somssich, I.E. The WRKY superfamily of plant transcription factors. Trends Plant Sci. 2000, 5, 199-206. [CrossRef]

18. Van Verk, M.C.; Pappaioannou, D.; Neeleman, L.; Bol, J.F.; Linthorst, H.J. A novel WRKY transcription factor is required for induction of PR-1a gene expression by salicylic acid and bacterial elicitors. Plant Physiol. 2008, 146, 1983-1995. [CrossRef]

19. Guo, C.L.; Guo, R.; Xu, X.; Gao, M.; Li, X.; Song, J.; Zheng, Y.; Wang, X. Evolution and expression analysis of the grape (Vitis vinifera L.) WRKY gene family. J. Exp. Bot. 2014, 65, 1513-1528. [CrossRef]

20. Wu, K.L.; Guo, Z.J.; Wang, H.H.; Li, J. The WRKY family of transcription factors in rice and Arabidopsis and their origins. DNA Res. 2005, 12, 9-26. [CrossRef]

21. Ishiguro, S.; Nakamura, K. Characterization of a cDNA encoding a novel DNA-binding protein, SPF1, that recognizes SP8 sequences in the $5^{\prime}$ upstream regions of genes coding for sporamin and $\beta$-amylase from sweet potato. Mol. Gen. Genet. 1994, 244, 563-571. [CrossRef]

22. Rushton, P.J.; Torres, J.T.; Parniske, M.; Wernert, P.; Hahlbrock, K.; Somssich, I.E. Interaction of elicitor-induced DNA-binding proteins with elicitor response elements in the promoters of parsley PR1 genes. EMBO J. 1996, 15, 5690-5700. [CrossRef]

23. Dong, J.X.; Chen, C.H.; Chen, Z.X. Expression profiles of the Arabidopsis WRKY gene superfamily during plant defense response. Plant Mol. Biol. 2003, 51, 21-37. [CrossRef]

24. Qiu, Y.P.; Jing, S.J.; Fu, J.; Li, L.; Yu, D.Q. Cloning and analysis of expression profile of 13 WRKY genes in rice. Chin. Sci. Bull. 2004, 49, 2159-2168. [CrossRef] 
25. Cui, Q.; Yan, X.; Gao, X.; Zhang, D.-M.; He, H.-B.; Jia, G.-X. Analysis of WRKY transcription factors and characterization of two Botrytis cinerea-responsive LrWRKY genes from Lilium regale. Plant Physiol. Biochem. 2018, 127, 525-536. [CrossRef] [PubMed]

26. Du, F.; Fan, J.; Wang, T.; Wu, Y.; Grierson, D.; Gao, Z.; Xia, Y. Identification of differentially expressed genes in flower, leaf and bulb scale of Lilium oriental hybrid 'Sorbonne' and putative control network for scent genes. BMC Genom. 2017, 18, 899. [CrossRef] [PubMed]

27. Wang, W.; Su, X.; Tian, Z.; Liu, Y.; Zhou, Y.; He, M. Transcriptome profiling provides insights into dormancy release during cold storage of Lilium pumilum. BMC Genom. 2018, 19, 196. [CrossRef] [PubMed]

28. Ding, L.; Wu, Z.; Teng, R.; Xu, S.; Cao, X.; Yuan, G.; Zhang, D.; Teng, N. LlWRKY39 is involved in thermotolerance by activating LlMBF1c and interacting with LlCaM3 in lily (Lilium longiflorum). Hortic. Res. 2021, 8, 36. [CrossRef]

29. Wu, Z.J.; Li, X.H.; Liu, Z.W.; Li, H.; Wang, Y.X.; Zhuang, J. Transcriptome-wide identification of Camellia sinensis WRKY transcription factors in response to temperature stress. Mol. Gen. Genom. 2016, 291, 255-269. [CrossRef]

30. Shi, W.; Hao, L.; Li, J.; Liu, D.; Guo, X.; Li, H. The Gossypium hirsutum WRKY gene GhWRKY39-1 promotes pathogen infection defense responses and mediates salt stress tolerance in transgenic Nicotiana benthamiana. Plant Cell Rep. 2014, 33, 483-498. [CrossRef]

31. Bold, O.; Jeevan, R.J.; Lim, Y.P.; Vanjildorj, E. Differentiation of wheat WRKY transcription factor TaWRKY10 gene expression in abiotic stress resistance. Mong. J. Agric. Sci. 2015, 13, 136-140. [CrossRef]

32. Qiu, Y.; Yu, D. Over-expression of the stress-induced OsWRKY45 enhances disease resistance and drought tolerance in Arabidopsis Environ. Exp. Bot. 2009, 65, 35-47. [CrossRef]

33. Zhou, Q.Y.; Tian, A.G.; Zou, H.F.; Xie, Z.M.; Lei, G.; Huang, J.; Wang, C.M.; Wang, H.W.; Zhang, J.S.; Chen, S.Y. Soybean WRKY-type transcription factor genes, GmWRKY13, GmWRKY21, and GmWRKY54, confer differential tolerance to abiotic stresses in transgenic Arabidopsis plants. Plant Biotechnol. J. 2008, 6, 486-503. [CrossRef] [PubMed]

34. Satapathy, L.; Singh, D.; Ranjan, P.; Kumar, D.; Kumar, M.; Prabhu, K.V.; Mukhopadhyay, K. Transcriptome-wide analysis of WRKY transcription factors in wheat and their leaf rust responsive expression profiling. Mol. Gen. Genom. 2014, 289, 1289-1306. [CrossRef] [PubMed]

35. Ding, M.; Chen, J.; Jiang, Y.; Lin, L.; Cao, Y.; Wang, M.; Zhang, Y.; Rong, J.; Ye, W. Genome-wide investigation and transcriptome analysis of the WRKY gene family in Gossypium. Mol. Gen. Genom. 2015, 290, 151-171. [CrossRef] [PubMed]

36. Maeo, K.; Hayashi, S.; Kojima-Suzuki, H.; Morikami, A.; Nakamura, K. Role of conserved residues of the WRKY domain in the DNA-binding of tobacco WRKY family proteins. Biosci. Biotechnol. Biochem. 2001, 65, 2428-2436. [CrossRef] [PubMed]

37. Cai, H.; Tian, S.; Dong, H. Large scale in silico identification of MYB family genes from wheat expressed sequence tags. Mol. Biotechnol. 2012, 52, 184-192. [CrossRef] [PubMed]

38. Remm, M.; Storm, C.E.; Sonnhammer, E.L. Automatic clustering of orthologs and in-paralogs from pairwise species comparisons. J. Mol. Biol. 2001, 314, 1041-1052. [CrossRef]

39. Miyamoto, T.; Takada, R.; Tobimatsu, Y.; Suzuki, T.; Yamamura, S.M.; Osakabe, K.; Osakabe, Y.; Sakamoto, M.; Umezawa, T. Double knockout of OsWRKY36 and OsWRKY102 boosts lignification with altering culm morphology of rice. Plant Sci. 2020, 286, 110466. [CrossRef] [PubMed]

40. Cui, X.W.; Zhang, Y.; Qi, F.Y.; Gao, J.; Chen, Y.W.; Zhang, C.L. Overexpression of a moso bamboo (Phyllostachys edulis) transcription factor gene PheWRKY1 enhances disease resistance in transgenic Arabidopsis thaliana. Botany 2013, 91, 486-494. [CrossRef]

41. Jiang, Y.; Duan, Y.; Yin, J.; Ye, S.; Zhu, J.; Zhang, F.; Lu, W.; Fan, D.; Luo, K. Genome wide identification and characterization of the Populus WRKY transcription factor family and analysis of their expression in response to biotic and abiotic stresses. J. Exp. Bot. 2014, 65, 6629-6644. [CrossRef]

42. Fan, X.; Guo, Q.; Xu, P.; Gong, Y.; Shu, H.; Yang, Y.; Ni, W.; Zhang, X.; Shen, X. Transcriptome-wide identification of salt-responsive members of the WRKY gene family in Gossypium aridum. PLoS ONE 2015, 10, e0126148. [CrossRef] [PubMed]

43. Jiang, Y.; Deyholos, M.K. Comprehensive transcriptional profiling of $\mathrm{NaCl}$ stressed Arabidopsis roots reveals novel classes of responsive genes. BMC Plant Bio. 2006, 6, 25.

44. Ramamoorthy, R.; Jiang, S.Y.; Kumar, N.; Venkatesh, P.N.; Ramachandran, S. A comprehensive transcriptional profiling of the WRKY gene family in rice under various abiotic and phytohormone treatments. Plant Cell Physiol. 2008, 49, 865-879. [CrossRef]

45. Peng, X.X.; Hu, Y.J.; Tang, X.K.; Zhou, P.L.; Deng, X.B.; Wang, H.H.; Guo, Z.J. Constitutive expression of rice WRKY30 gene increases the endogenous jasmonic acid accumulation, $P R$ gene expression and resistance to fungal pathogens in rice. Planta 2012, 236, 1485-1498. [CrossRef]

46. Wang, H.H.; Meng, J.; Peng, X.X.; Tang, X.K.; Zhou, P.L.; Xiang, J.H.; Deng, X.B. Rice WRKY4 acts as a transcriptional activator mediating defense responses toward Rhizoctonia solani, the causing agent of rice sheath blight. Plant Mol. Biol. 2015, 89, 157-171. [CrossRef] [PubMed]

47. Zhang, J.; Peng, Y.L.; Guo, Z.J. Constitutive expression of pathogen-inducible OsWRKY31 enhances disease resistance and affects root growth and auxin response in transgenic rice plants. Cell Res. 2008, 18, 508-521. [CrossRef] [PubMed]

48. Yu, F.; Huaxia, Y.; Lu, W.; Wu, C.; Cao, X.; Guo, X. GhWRKY15, a member of the WRKY transcription factor family identified from cotton (Gossypium hirsutum L.), is involved in disease resistance and plant development. BMC Plant Biol. 2012, 12, 144. [CrossRef] [PubMed]

49. Chen, L.; Song, Y.; Li, S.; Zhang, L.; Zou, C.; Yu, D. The role of WRKY transcription factors in plant abiotic stresses. Biochim. Biophys. Acta 2012, 1819, 120-128. [CrossRef] [PubMed] 
50. Matsui, A.; Ishida, J.; Morosawa, T.; Mochizuki, Y.; Kaminuma, E.; Endo, A.T.; Okamoto, M.; Nambara, E.; Nakajima, M.; Kawashima, M.; et al. Arabidopsis transcriptome analysis under drought, cold, high-salinity and ABA treatment conditions using a tiling array. Plant Cell Physiol. 2008, 49, 1135-1149. [CrossRef] [PubMed]

51. Yokotani, N.; Sato, Y.; Tanabe, S.; Chujo, T.; Shimizu, T.; Okada, K.; Yamane, H.; Shimono, M.; Sugano, S.; Takatsuji, H. WRKY76 is a rice transcriptional repressor playing opposite roles in blast disease resistance and cold stress tolerance. J. Exp. Bot. 2013, 64, 5085-5097. [CrossRef] [PubMed]

52. Yang, X.; Yang, Y.-N.; Xue, L.-J.; Zou, M.-J.; Liu, J.-Y.; Chen, F.; Xue, H.-W. Rice ABI5-Like1 regulates abscisic acid and auxin responses by affecting the expression of ABRE-containing genes. Plant Physiol. 2011, 156, 1397-1409. [CrossRef]

53. Li, M.-Y.; Xu, Z.-S.; Tian, C.; Huang, Y.; Wang, F.; Xionga, A.-S. Genomic identification of WRKY transcription factors in carrot (Daucus carota) and analysis of evolution and homologous groups for plants. Sci. Rep. 2016, 6, 23101. [CrossRef]

54. Zhang, C.Q.; Xu, Y.; Lu, Y.; Yu, H.X.; Gu, M.H.; Liu, Q.Q. The WRKY transcription factor OsWRKY78 regulates stem elongation and seed development in rice. Planta 2011, 234, 541-554. [CrossRef] [PubMed]

55. Emanuelsson, O.; Nielsen, H.; Brunak, S.; von Heijne, G. Predicting subcellular localization of proteins based on their N-terminal amino acid sequence. J. Mol. Biol. 2000, 300, 1005-1016. [CrossRef]

56. Ross, C.A.; Liu, Y.; Shen, Q.J. The WRKY gene family in rice (Oryza sativa). J. Integr. Plant Biol. 2007, 49, 827. [CrossRef]

57. Bailey, T.L.; Boden, M.; Buske, F.A.; Frith, M.; Grant, C.E.; Clementi, L.; Ren, J.; Li, W.W.; Noble, W.S. MEME SUITE: Tools for motif discovery and searching. Nucleic Acids Res. 2009, 37, W202-W208. [CrossRef]

58. Kumar, S.; Stecher, G.; Tamura, K. MEGA7: Molecular evolutionary genetics analysis version 7.0 for bigger datasets. Mol. Biol. Evol. 2016, 33, 1870-1874. [CrossRef]

59. Edgar, R.C. MUSCLE: A multiple sequence alignment method with reduced time and space complexity. BMC Bioinform. 2004, 32, 1792-1797.

60. Murashige, T.; Skoog, F. A revised medium for rapid growth and bio assays with tobacco tissue cultures. Physiol. Plant 1962, 3, 473-497. [CrossRef]

61. Hsieh, T.F.; Huang, J.W. Effect of film-forming polymers on control of lily leaf blight caused by Botrytis elliptica. Eur. J. Plant Pathol. 1999, 5, 501-508. [CrossRef]

62. Livak, K.J.; Schmittgen, T.D. Analysis of relative gene expression data using real-time quantitative PCR and the 2- $\Delta \Delta C T$ method. Methods 2001, 25, 402-408. [CrossRef] [PubMed] 